\title{
The Influence of Balance and Flexibility on the Performance of Freestyle Swimming
}

\section{Elvira Nikšić ${ }^{1}$ \\ (iD) http://orcid.org/0000-0002-1849-9693}

Faculty of Educational Sciences, University of Sarajevo, Bosnia and Herzegovina

\section{Edin Beganović \\ iD http://orcid.org/0000-0002-5190-6035}

Faculty of Physical Education and Sport, University of Sarajevo, Bosnia and Herzegovina

\section{Marko Joksimović \\ iD http://orcid.org/0000-0003-4232-5033}

National Football Club, Podgorica, Montenegro

\section{Adnan Mušović (iD) https://orcid.org/0000-0002-3578-5165}

Marko Miljanov Elementary school, Bijelo Polje, Montenegro

Received: March 27, 2020

DOI: $10.30655 /$ besad.2020.28
Accepted: June 4, 2020

Online Published: June 10, 2020

https://doi.org/10.30655/besad.2020.28

\begin{abstract}
The aim of this research was to determine the influence of motor abilities on the success of performing a freestyle swimming, pre and post the completed swimming training program. The study was conducted on a sample of 90 female students, aged 11-12 years, fifth graders from primary schools in Novi Grad Municipality in Sarajevo, using 6 motor variables and 1 criterion. Regression analysis was used to determine the effect of balance and flexibility on the freestyle swimming performance. Analyzing the presented results of the regression analysis, it was found that after the pre-test measurement of the variables for estimating the balance, the following predictor motor variable had the greatest and statistically significant influence on the criterion variable: standing upright on the balance beam with eyes open $(B E T A)=.581$, which is significant at the level of $p<.001$. For flexibility, the following predictor motor variable is: upper body bent forward while sitting with legs side by side $(B E T A)=.411$, which is significant at the p<.001 level. After the post-test measurement of the variables for the assessment of motor abilities (balance and flexibility), the same variables as for the pre-test measurement had the statistically significant influence on the criterion variable (freestyle swimming of the sections $25 \mathrm{~m}$ long crawl, chest or back swimming). At standing on the right leg longitudinally, open-eyed, on the balance bench $(B E T A)=.448$, which is significant at the level of $p<.001$, and in flexibility the variable - bench ab with legs side by side $(B E T A)=.463$, which is significant at the level of $p<.001$. All movements in swimming require well-developed flexibility (mobility), and in particular the mobility of the torso and upper extremities.
\end{abstract}

Keywords: Motor performance, adolescents, training, ability, amplitude

\section{${ }^{1}$ Corresponding author: Elvira Nikšić}

Faculty of Educational Sciences, Skenderija St. No. 72, 71000, Sarejova, Bosnia and Herzegovina elvira.beganovic1982@gmail.com 


\section{Introduction}

Flexibility is the ability to perform movements with a large amplitude of body parts in individual joint systems, while balance implies the body's balance to remain at rest or movement. Depending on the swimming technique being taught, there are major differences in the mobility of individual joints. Flexibility can relatively be well developed by applying different kinesiological content (Beganović, 2011). There are different types of flexibility: dynamic flexibility - the ability to perform dynamic movements through the full range of motion in a particular joint, static-active flexibility - the ability to achieve and maintain a stretched position in a particular joint, using only the work of agonists and synergists, while an antagonistic muscle group is stretched, static-passive flexibility - the ability to reach and maintain a stretched position in a particular joint using one's body weight, extremities, or a particular device. Flexibility development work should play an important role in any swimming training program. It is known that swimmers with free, back or dolphin technique have to pay more attention to arm and shoulder exercises, because injuries of these swimmers are most commonly in the shoulder joint. In contrast to the breaststroke swimmers, the flexibility of the shoulder joint is not a crucial component for success, but rather the flexibility of the pelvic, knee, and dorsal flexion of the foot. Due to a completely different motor movement in the water, the work of the feet is a very significant propulsive factor for swimmers in the chest technique, therefore the most common injuries occur in the knee joint (Krstić, Kitanović-Krstić, \& Čavka, 2012). Swimming develops basic motor abilities and contributes to the development of cognitive (intellectual) abilities. It contributes to increasing the strength and endurance of the muscular system, coordination and improving circulation. Successful freestyle swimming requires repetitive strength and coordination, as all movements such as arm, leg and whole body movements plus breathing reduce coordination and repetitive strength, but also balance and flexibility, high joint mobility (Nikšić, Beganović, Joksimović, Nasrolahi \& Đoković, 2019). By working on flexibility, the technique of swimming improves, and thus the result (Šiljag \& Grčić-Zubčević, 2007). Propulsion will be reduced if the swimmer is unable to perform the maximum amplitude of movement in the shoulder joint. Also the propulsion will be reduced if the swimmer does not have optimal foot extension. These examples speak to the importance of flexibility for swimming. Improving flexibility affects muscle length and helps developing muscle strength and helps preventing injury (Volčanšek, 2002). In mastering one of the swimming techniques, balance is essential in making a strong reflection from the starting block. Starting and moving the body weight forward disturbs the balance, after which a strong reflection and momentum of the hands are exercised. When starting from the block which is located at the pool, well-developed flexibility is required, first in the ankle joint and knee joint, and then in the hip joint, as well as when performing arm movements in any technique (Mirvić, 2015). Mandić, Okičić, \& Aleksandrovic, (2007) stated that the success of swimming techniques was influenced by the overall anthropological status. Torlakovic (2009) investigated the effects of an experimental non-swimmer training program on the dynamics of learning basic swimming elements in boys aged 8 to 10 years. The results of the study showed that boys who practiced sports adopted the basic elements of swimming quickly and efficiently. In support of this, athletes are likely to have a greater need for achievement, perception and motor abilities, as well as a greater motivation for success. The aim of this research is to determine the magnitude of the influence of motor abilities (balance and flexibility) on the success of performing freestyle swimming, before and after the completed swimming training program.

\section{Method}

The sample was 90 female students, aged $11.63 \pm 0.70$ years, 5 th graders from primary schools in Novi Grad Municipality in Sarajevo. The research was in accordance with the Helsinki Convention and the respondents participated voluntarily providing a written consent from their legal guardians. All students were measured with 6 variables designed to cover well their motor abilities (balance and flexibility) and one criterion variable. Six variables designed to cover the area of primary motor dimensions were used to assess subjects' motor abilities: variables for assessing balance (Balance of Right Leg -BRL, Balance of Left Leg - BLL, Balance of Both Leg - BBL); variables for assessing flexibility (Front Splits - FS, Lateral Splits - LS, Sit and Reach - SR) and 1 criterion variable for evaluating the performance of a freestyle swimming, technique rating - ST (25 $\mathrm{m}$ freestyle swimming). Working program conducted in this research is conceived on the 
principles of theory and practice that treats the methodology of working with beginners. The core program covered the activity through time period (for four months, the subjects were divided into two groups of 45 students during that period, for two months per group), number of training units: 16 block classes per group (two times a week), duration of one teaching block class 90 minutes, in order to determine the magnitude of the influence of motor abilities (balance and flexibility) on the success of performing a freestyle swimming, before and after the completed swimming training program. Class structure: Introductory part of the class (introductory word and organizational preparations) - 5 minutes. Preparation part of the class (shaping exercises and accustoming to the water) - 10 minutes. The main part of the class (basic program) - 60 minutes. Sports training exercises - crawl, back and chest swimming (dry exercising, water exercising, legs exercises, arms exercises, breathing exercises, swimming techniques exercises in full coordination). Final part of the class (relaxing exercises and games) - 15 minutes. The data obtained in this study were processed using SPSS 16.0 software. Regression analysis was applied in order to determine the influence of motor abilities (balance and flexibility) on the success of performing freestyle swimming, before and after the completed swimming training program. Regression analysis was applied to determine the influence of motor abilities (balance and flexibility), designated as input or predictor set, on swimming performance, designated as output or criterion variable. Based on the magnitude of the multiple regression (R), the joint variance (R square) is explained only if it is statistically significant.

Table 1. Descriptive Statistics of Morphological Characteristics

\begin{tabular}{lcc}
\hline Variables & $\mathrm{N}$ & $\mathrm{M} \pm \mathrm{SD}$ \\
\hline Body height $(\mathrm{cm})$ & & $147.31 \pm 7.43$ \\
Body weight $(\mathrm{kg})$ & 90 & $40.28 \pm 8.79$ \\
Body Mass Index $(\mathrm{kg} / \mathrm{m} 2)$ & & $18.51 \pm 3.02$ \\
Age & & $11.63 \pm 0.70$ \\
\hline
\end{tabular}

Table 1 presenting the basic anthropometric parameters of the subject (height, weight and body mass index), i.e. their mean and standard deviation. The average height of the subjects is 147.31 $7.43 \mathrm{~cm}$, the average weight is $40.28 \pm 8.79 \mathrm{~kg}$ and the average $\mathrm{BMl}$ is $18.51 \pm 3.02$.

Table 2. Assessment Criteria

\begin{tabular}{cl}
\hline MARK & \multicolumn{1}{c}{ The Level of Mastered Technique } \\
\hline E & $\begin{array}{l}\text { A total non-swimmer. } \\
\text { Floater. There are major mistakes in performing coordination elements of } \\
\text { crawl technique and complete absence of breathing technique. }\end{array}$ \\
C & $\begin{array}{l}\text { Half-swimmer. There are obvious mistakes in performing some coordination } \\
\text { elements of crawl technique, and some mistakes in breathing technique. }\end{array}$ \\
B & $\begin{array}{l}\text { Satisfying performance of crawl technique, with insignificant mistakes in hand } \\
\text { and leg coordination. }\end{array}$ \\
A & $\begin{array}{l}\text { Techniques which are carried out with the optimal angle of attack (crawl), by a } \\
\text { proper coordination and breathing. }\end{array}$ \\
\hline
\end{tabular}

\section{Results}

Figure 1 shows that, after the pre-test measurement, the subjects received the following grades: $46 \%$ received grade $1,27 \%$ received grade $2,27 \%$ received grade 3 , while none of the subjects received grades 4 and 5 . After the post-test measurement, none of the subjects were rated with grade 1 , which was a great success considering the high number of non-swimmers after the pre-test measurement. $28 \%$ of the subjects received grade $2,34 \%$ of the subjects received grade 3. $28 \%$ received grade 4 and $10 \%$ received grade 5 . The grades improved for all subjects after the post-test measurement. It should also be noted that there were no more complete non-swimmers with grade $1-\mathrm{E}$ after the post-test measurement $(0 \%)$. The percentage of non-swimmers, according to the post-test measurement, was represented by the students who belong in the category of floaters with grade 2-D (28\% of the subjects). The students swam the freestyle 
technique for $25 \mathrm{~m}$. They had the possibility to choose one of the swimming techniques (crawl, backstroke or breaststroke) which they mastered the best after the training.

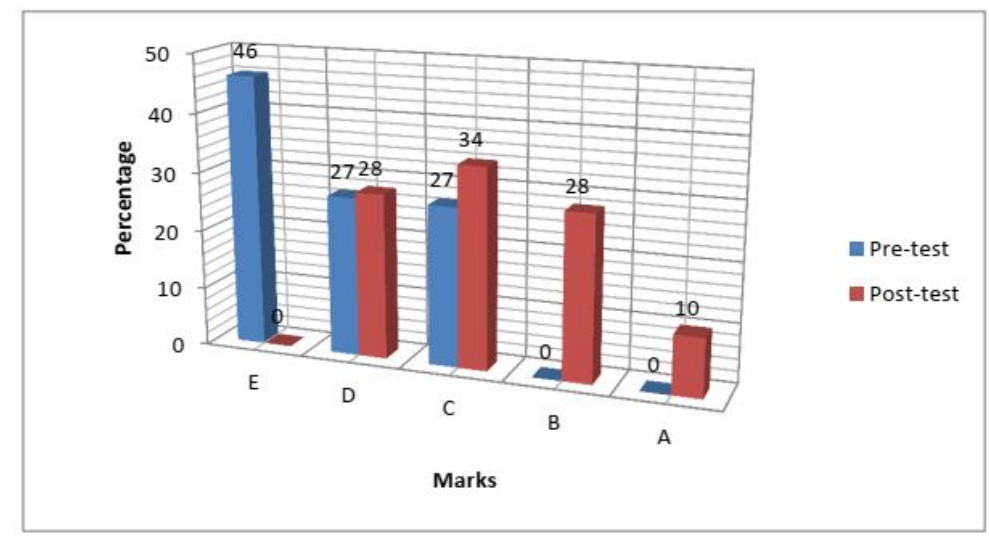

Figure 1. Pre and Post-tests Measurements

Table 3. Display of Values oOf Multiple Correlation Coefficient Between the Predictor Variables and the Criterion

\begin{tabular}{cccccc}
\hline Model & \multicolumn{2}{c}{ Unstandard Coefficients } & Standard Coefficients & $\mathrm{t}$ & $\mathrm{P}$ \\
\cline { 2 - 3 } BRL & $\mathrm{B}$ & Std. Error & Beta & & \\
BLL & .021 & .005 & .581 & 4.014 & .001 \\
BBL & .004 & .005 & .111 & .788 & .433 \\
$\mathrm{R}=.778 \quad \mathrm{R}^{2}=0.60$ & $\mathrm{~F}=43.938$ & $\mathrm{p}=.001$ & .114 & .823 & .413 \\
\hline
\end{tabular}

Rather high coefficient of multiple correlation $\mathrm{R}=.778$ indicates a significant statistical influence of the variables for estimating balance on the criterion. Following predictor motor variable had the greatest and statistically significant effect on the ST criterion variable: BRL (BETA) $=.581$, which is significant at the $p<.000$ level.

Table 4. Display of Values of Coefficient of Multiple Correlation Between Predictor Variables and Criterion

\begin{tabular}{|c|c|c|c|c|c|}
\hline \multirow[t]{2}{*}{ Model } & \multicolumn{2}{|c|}{ Unstandard Coefficients } & \multirow{2}{*}{$\frac{\text { Standard. Coefficients }}{\text { Beta }}$} & \multirow[t]{2}{*}{$\mathrm{t}$} & \multirow{2}{*}{$\mathrm{p}$} \\
\hline & $B$ & Std. Error & & & \\
\hline SR & .035 & .009 & .411 & 3.724 & .001 \\
\hline FS & .006 & .007 & .145 & .852 & .397 \\
\hline LS & .003 & .007 & -.069 & -.414 & .680 \\
\hline $\mathrm{R}=.461 \quad \mathrm{R}^{2}=.212$ & $F=7.717$ & $p=.001$ & & & \\
\hline
\end{tabular}

High multiple correlation coefficient of $\mathrm{R}=.461$ indicates a significant statistical influence of the variables for assessing flexibility on the criterion. Following predictor motor variable had the greatest and statistically significant effect on the ST criterion variable: SR (BETA) $=.411$, which is significant at the $p<.000$ level. 
Table 5. Display of Values of Multiple Correlation Coefficient Between the Predictor Variables and the Criterion

\begin{tabular}{|c|c|c|c|c|c|}
\hline \multirow[t]{2}{*}{ Model } & \multicolumn{2}{|c|}{ Unstandard Coefficients } & \multirow{2}{*}{$\frac{\text { Standard. Coefficients }}{\text { Beta }}$} & \multirow[t]{2}{*}{$\mathrm{t}$} & \multirow[t]{2}{*}{$\mathrm{p}$} \\
\hline & $\mathrm{B}$ & Std. Error & & & \\
\hline$B R L$ & .023 & .007 & .448 & 3.348 & .001 \\
\hline BLL & .011 & .007 & 200 & 1.522 & .132 \\
\hline $\mathrm{BBL}$ & .011 & .006 & .200 & 1.721 & .089 \\
\hline$R=.829 \quad R^{2}=.687$ & $7 \quad F=62$ & $p=.001$ & & & \\
\hline
\end{tabular}

Rather high coefficient of multiple correlation $\mathrm{R}=.829$ indicates a significant statistical influence of the variables for estimating balance on the criterion. The following predictor motor variable had the greatest and statistically significant influence on the ST criterion variable: BLR $(B E T A)=.448$, which was significant at the $p<.001$ level.

Table 6. Display of Values of Coefficient of Multiple Correlation Between Predictor Variables and Criterion

\begin{tabular}{cccccc}
\hline Model & \multicolumn{2}{c}{ Unstandard Coefficients } & Standard. Coefficients & $\mathrm{t}$ & $\mathrm{P}$ \\
\cline { 2 - 4 } $\mathrm{SR}$ & $\mathrm{B}$ & Std. Error & Beta & & \\
FS & .058 & .012 & .463 & 4.704 & .001 \\
LS & .002 & .005 & .048 & .487 & .682 \\
$\mathrm{R}=.542 \mathrm{R}^{2}=.294$ & $\mathrm{~F}=11.909 \mathrm{p}=.001$ & .003 & .143 & 1.478 & .143 \\
\hline
\end{tabular}

High multiple correlation coefficient of $\mathrm{R}=.542$ indicates a significant statistical influence of the variables for assessing flexibility on the criterion. The following predictor motor variable had the greatest and statistically significant influence on the ST criterion variable: SR (BETA) $=.463$, which is significant at the $p<.000$ level.

\section{Discussion}

For a successful result in swimming, performing any of the swimming techniques (i.e. freestyle), students need to have well-developed basic motor abilities. They are involved in solving motor tasks and allow them to move successfully, whether they are acquired through training or not. These are the basis of all motor learning and directly influence sports performance (Malacko \& Rađo, 2004). Okičić, Jorgić, Mandić, Thanopoulos \& Jovanović (2012), in a sample of 30 subjects aged 9 to 12 years, attempt to determine the baseline and specific motor abilities relationships with breaststroke results in young swimmers. The results of the regression analysis indicate that all basic motor variables used had a statistically significant correlation with the swimming result at $100 \mathrm{~m}$ breaststroke ( $p<.001$ ), with $\mathrm{R}$ being 0.78 and common variability (R2) explained by $0.61 \%$. Individually observed variables did not have a statistically significant effect on the swimming result. This indicates the need to develop all the basic motor abilities. The data thus obtained indicate that in the training process with the younger categories, optimal conditions should be created for the development of all motor abilities that may have an effect on swimming efficiency in the breaststroke technique. Stoiljković (2003), in breaststroke swimmers, the most important component of success is considered to be flexibility in the pelvic, knee, and hip joints. Rađo, Pivač \& Wolf, (1995), on a sample of 87 subjects, analyzed the influence of basic motor abilities in the process of learning and improving sports swimming techniques (crawl, backstroke, breaststroke). Based on the regression analysis, successful coordination of sports, swimming, and backstroke techniques requires good coordination, speed, as well as flexibility of the shoulder joint and feet in dorsal and plantar flexion. In his doctoral dissertation Volčanšek (1979) examined the influence of anthropometric and motor dimensions on swimming performance in adolescents beginners. In a sample of 188 subjects, 113 males and 75 females in Zagreb, by canonical correlation analysis, the author obtains one dimension between anthropometry and swimming, and two pairs of canonical dimensions between motor subspace and swimming results. The first pair talks about 
swimming performance of those subjects who possess: coordination abilities, flexibility in the shoulder joint, the success of solving new motor tasks and speed of movement frequency. The second canonical factor is defined by explosive power, agility and repetitive power, and projection to it is only by the technique of breaststroke. Vidović (2000), in her dissertation included a study on a sample of 181 male subjects. The measurements were made using 16 morphological and 21 variables for the assessment of general motor abilities and 23 variables for the evaluation of stylized forms of movement in water (specific motor abilities). The results of the regression analysis of swimming with different techniques at $50 \mathrm{~m}$ gave sufficient information about the influence of the predictor system on the variance in swimming performance. Six dimensions are isolated in the area of motor abilities: repetitive torso strength, explosive power, flexibility, movement frequency, coordination, and general muscular endurance. Successful work (well-developed flexibility) and proper coordination of arm and leg movements, plus breathing (Kazazović, 2008) are required to successfully master one of the swimming techniques (freestyle swimming). Torlaković (2009), in his research showed that boys who already practiced any sports more effectively adopted the basic elements of swimming, compared to children who have never engaged in sports before. This indicates that motor abilities are very important for swimming, as students who practice a sport have better motor abilities and thus achieve better swimming success. In this study, students who were not active athletes showed poorer results. After a pre-test examination of the level of swimming knowledge, it was observed that grade 1 was given to 47 students, which is $95.92 \%$. At the seventh, eighth and ninth class, the number of students with grades 3 and 2 increased. With the increase in the number of training classes, students were able to master the basic elements of swimming better and more and more students were moving from skating to swimming. Students received higher grades, and thus received the highest grade of 5 in fourteenth training, two students (4.08\%). Regardless of this type of progress, the highest number of students still received a grade 1, 29 of them, which is $59.18 \%$. Gradually, students received better grades, and thus gained better swimming abilities. Thus, seven students received a grade of one in the final testing, which is a great success considering the number of non-swimmers after the pre-test measurement. Most students in the post-test measurement swam the crawl technique with proper work of the arms, legs and breathing, which was to be expected given that the subjects were boys. The reason these students did not learn how to swim is probably because some students need more time to adapt to the aquatic environment and swim, as well as their physical inactivity and therefore less developed motor abilities, as shown only by research into where students who are engaged in some sport were more successful in mastering basic swimming techniques. In a sample of $90 \mathrm{~V}$ grade students, ages 11 to 12 , respondents attempted to determine the impact of motor abilities (repetitive strength and coordination) on the performance of a freestyle swimming, before and after a swim training program was completed. 6 motor variables and one criterion were used to assess basic motor abilities. Regression analysis was used to determine the effect of repetitive power and coordination on the performance of the freestyle swimming. Analyzing the presented results of the regression analysis, it can be concluded that after the initial and post-test measurements of the repetitive power variables, the following predictor motor variables had the greatest and statistically significant influence on the ST criterion variable: sit-ups, push-up, deep squat, and in coordination the following predictor motor variables: throwing a ball from hand to hand over head for 30 seconds, coordination with a stick, and air rotation. Which is to be expected, as all movements in swimming such as movements of the arms, legs and the whole body plus breathing are dependent to coordination and repetitive power (Nikšić, Beganović, Joksimović, Nasrolahi \& Đoković, 2019).

\section{Conclusion}

The regression analysis was applied to determine the influence of motor variables (balance and flexibility) on the success of performing freestyle swimming, before and after the completed swimming training program. One variable was used as the criterion in this analysis, ST $(25 \mathrm{~m}$ freestyle swim). Analyzing the presented results of the regression analysis, it can be concluded that after the initial and post-test measurements, the following predictor motor variable had the greatest and statistically significant influence on the ST criterion variable: BRL (balance of right leg), and with flexibility the following predictor motor variable: SR (sit and reach). This should have 
been expected, because when doing a freestyle swim, subjects started from the starting block or the edge of the pool, which required a well-developed balance. All the students examined had a dominant right leg, and therefore the statistically significant influence on the criterion variable was the predictor variable BRL (balance of right leg). All movements in swimming require well-developed flexibility (mobility), and in particular the mobility of the torso and upper extremities. Based on the presented results of the regression analysis, before and after attending to the swimming program, it can be established that a rather high coefficient of multiple correlation of the motor variables system (balance and flexibility) and the criterion variable is present, indicating that the predictor system of motor variables has a statistically significant influence on the criterion variable, as shown by the results of the post-test measurement of the freestyle swimming.

\section{References}

Beganović, E. (2011). Effects of a Neoclassical Program on Elementary Swimming Training. Unpublished Master thesis. Faculty of Sport and Physical Education, University of Sarajevo: Sarajevo.

Kazazović, B. (2008). Swimming. 3rd edition. Grafičar promet: Sarajevo.

Krstić, M., Kitanović-Krstić, R., \& Čavka, A. (2012). Application of stretching exercises to the development of flexibility in the swimmer's training process. Proceedings of the 21st Summer School of Kinesiologists of the Republic of Croatia, "Intensification of the Exercise Process in the Fields of Education, Sport, Sports Recreation and Kinesitherapy", 444-450.

Mandić, D., Okičić, T., Aleksandrović, M. (2007). Swimming. Nis: Serbia.

Malacko, J., \& Rađo, I. (2004). Technology of sports and sports training. Sarajevo: Faculty of Sport and Physical Education.

Mirvić, E. (2015). Swimming. Faculty of Sport and Physical Education, University of Sarajevo: Sarajevo.

Nikšić, E., Beganović, E., Joksimović M., Nasrolahi, S., \& Đoković, I. (2019). The impact of strength and coordination on the success of freestyle swimming performance. European Journal of Physical Education and Sport Science. 5(11): 10-22. DOl:10.5281/zenodo.3364090.

Okičić, T., Jorgić, B., Mandić D., Thanopoulos, V., \& Jovanović, P. (2012). Relationships of basic and specific motor abilities with the results of breaststroke swimming in young swimmers. Sports Science \& Health. 2(1): 16-21. DOI: 10.7251/SSH1201016O.

Rađo, I., Pivač, M., \& Wolf, B. (1995). Metric Characteristics of Tests for Assessment of Situational Motor Abilities in Swimming. Fis communication. Niš.

Stoiljković, S. (2003). Basics of general anthropomotorics. Nis: SKC-Nis.

Šiljag, K., \& Grčić-Zubčević, N. (2007). Construction and validation of measuring instruments for assessing swimmer flexibility in back technique. Proceedings of the 16th Summer School of Kinesiologists of the Republic of Croatia. (pp. 219-224). Croatian Kinesiology Association.

Torlaković, A. (2009). The effects of an intensive program of learning the basic elements of swimming in extracurricular activities on young children. HomoSporticus. 11, 2: 14-18.

Vidović, N. (2000). Relationship between morphological characteristics and motor readiness (ability) with the degree of adoption of stylized swimming movements in student youth. Unpublished Doctoral Dissertation. Faculty of physical culture, University of Sarajevo: Sarajevo.

Volčanšek, B. (1979). The influence of anthropometric and motor dimensions on swimming results. [Unpublished Doctoral Dissertation. Faculty of Physical Culture, University of Zagreb: Zagreb.

Volčanšek, B. (2002). The essence of swimming. Faculty of Kinesiology, University of Zagreb. 